\title{
Radiation dose and protection
}

\author{
Mark O. Baerlocher MD, Stefanie Leung MD, Murray Asch MD, Andy Myers MD
}

\section{Imaging examinations are guided by the ALARA principle ("as low as rea- sonably achievable") for radiation dose and exposure}

All studies should involve the minimum amount of radiation required to provide the required information.

\section{Computed tomography (CT) is associated with an increased risk of cancer because of the potential for higher doses of radiation com- pared with plain radiographs}

Nuclear medicine, interventional radiology and barium studies also have the potential for higher doses of radiation. There has been a large increase in the number of CT scans performed because of wider availability. ${ }^{2}$ In 2007, researchers estimated that $1.5 \%$ to $2 \%$ of all cancers in the United States in the future could be attributable to radiation exposure from CT scanning. ${ }^{3}$ By reducing the number of unnecessary scans and the radiation dose per scan, the total dose from CT imaging may be reduced. ${ }^{2}$ Shielding areas such as the breasts, the thyroid and gonadal tissue in some instances can also decrease exposure.

\section{Children are more susceptible than adults to the oncogenic effects of radiation}

Children have an increased risk from radiation exposure because of a longer expected lifespan and increased tissue radiosensitivity. Children also receive a larger relative dose of radiation because of their smaller size. ${ }^{1}$ Radiation-related risks to the fetus are greatest during the first trimester. As a general rule, younger patients are at greater risk of radiation-induced adverse effects than older patients, and females are more at risk than males.
The number of CT scans can be reduced by considering alternative imaging modalities such as ultrasound and magnetic resonance imaging where appropriate

Ultrasonography and magnetic resonance imaging are effective in detecting certain pathologies. Evidence-based guidelines are available to guide the selection of imaging for many common presenting complaints. ${ }^{4}$

The benefit versus harm of CT scanning as a screening tool in asymptomatic patients depends on the application

For example, CT colonography (or virtual colonography) has an accepted role in clinical care. ${ }^{5}$ However, full-body CT scanning to screen asymptomatic patients delivers a high radiation dose with an expected high false-positive rate.
CMAJ invites submissions to "Five things to know about ... ." Submit manuscripts online at http://mc.manuscriptcentral.com/cmaj

\section{References}

1. Brody AS, Frush DP, Huda W, et al. Radiation risk to children from computed tomography. Pediatrics 2007; 120:677-82

2. Hall EJ, Brenner DJ. Cancer risks from diagnostic radiology. Br J Radiol 2008;81:362-78.

3. Brenner DJ, Hall EJ. Computed tomography — an increasing source of radiation exposure. $N$ Engl J Med 2007;357:2277-84.

4. Canadian Association of Radiologists. Diagnostic imaging referral guidelines: a guide for physicians. Ottawa (ON): The Association; 2005. Available: www.car.ca/en/standards-guidelines.aspx (accessed 2011 Dec. 2).

5. El-Maraghi RH, Kielar AZ. CT colonography versus optical colonoscopy for screening asymptomatic patients for colorectal cancer a patient, intervention, comparison, outcome (PICO) analysis. Acad Radiol 2009;16:564-71.

Competing interests: Mark Baerlocher was the co-creator of an application for iPhone/iPad/ iPod that tracks radiation exposure and estimates the associated risks; he received no payment for this work. No competing interests declared by the other authors.

This article has been peer reviewed.

Affiliations: From the Department of Radiology (Baerlocher), Royal Victoria Hospital, Barrie, Ont.; the Department of Interventional Radiology (Baerlocher), University of California at San Diego, San Diego, Calif.; the School of Medicine (Leung), University of British Columbia, Vancouver, BC; and the Department of Radiology (Asch, Myers), Lakeridge Health Corporation, Oshawa, Ont

Correspondence to: Dr. Mark O. Baerlocher, mark.baerlocher@alumni.utoronto.ca

CMAJ 2012. DOI:10.1503/cmaj.090754 